В.С.Боровицкий

Эффективность и переносимость лечения по 2Б-режиму химиотерапии впервые выявленного деструктивного инфильтративного туберкулеза легких с использованием комбинированного противотуберкулезного препарата в лечебном учреждении Федеральной службы исполнения наказаний

Федеральное казенное учреждение "Лечебоное исправительное учреждение № 12" Управления Федеральной службы исполнения наказаний РФ по Кировской области: 613040, Кировская обл., Кирово-Чепецк

\title{
V.S.Borovitsky
}

\section{Efficacy and tolerability of anti-tuberculotic chemotherapy in patients with newly diagnosed cavitary infiltrative pulmonary tuberculosis and a high risk of drug resistance in prisons}

\begin{abstract}
Summary
In penitentiary hospitals, patients with infiltrative pulmonary tuberculosis and cavitation not having HIV infection were treated with combined antituberculosis therapy including Lomekomb. After 3 months of treatment, sputum culture conversion was observed in $73.5 \%$ of patients and cavity closure in $32.4 \%$. Adverse events were seen in $97.1 \%$ of cases, all of them were reversible. The most frequent adverse events were combined toxic and allergic reactions (67.6\% of patients) followed by toxic reactions (20.6\%) and allergic reactions ( $8.8 \%$ ) alone. Urticaria was observed in $17.6 \%$ of patients, blood eosinophilia in $73.5 \%$, and elevated transaminases in $82.4 \%$.

Key words: tuberculosis, Lomekomb, efficacy, side effects, Federal Penitentiary Service.
\end{abstract}

\section{Резюме}

В лечебных учреждениях Федеральной службы исполнения наказаний РФ среди больных деструктивным инфильтративным туберкулезом легких $(n=34)$, не инфицированных вирусом иммунодефицита человека и получающих лечение по 2Б-режиму химиотерапии с использованием комбинированного противотуберкулезного препарата Ломекомб, в первые 3 мес. пребывания в стационаре методом посева мокроты выявлено прекращение бактериовыделения у 73,5 \%, закрытие каверн - у 32,4\%. Частота устранимых побочных реакций составила $97,1 \%$. Токсико-аллергические реакции отмечены у $67,6 \%$, токсические - у 20,6 \%, аллергические - у $8,8 \%$, крапивница у $17,6 \%$, эозинофилия периферической крови - у 73,5\%, повышение трансаминаз в крови - у 82,4\% пациентов.

Ключевые слова: туберкулез, Ломекомб, эффективность лечения, побочное действие, Федеральная служба исполнения наказаний.

При превышении региональной частоты первичной множественной лекарственной устойчивости микобактерий туберкулеза (МБТ) > $5 \%$, а вторичной $>15 \%$ повышается риск заболевания лекарственноустойчивым туберкулезом. Поэтому рекомендуется использовать у впервые выявленных больных туберкулезом 2Б-режим химиотерапии $[1,2]$. Фундаментальные работы, посвященные побочному действию комбинированной химиотерапии туберкулеза легких, основаны на изучении больных в гражданских противотуберкулезных учреждениях [3]. Пациенты в лечебных учреждениях Федеральной службы исполнения наказаний (ФСИН) относятся преимущественно к категории социально запущенных, неблагополучных лиц с сочетанием отягощающих факторов и вредных привычек. Особенности переносимости противотуберкулезных препаратов (ПТП) у данной категории пациентов изучены мало. При исследовании выбрана самая распространенная форма - деструктивный инфильтративный туберкулез легких [4].

Целью проспективного одноцентрового сплошного исследования больных, не инфицированных вирусом иммунодефицита человека (ВИЧ), явилось изучение эффективности и переносимости лечения впервые выявленного деструктивного инфильтративного туберкулеза легких у больных по 2Б-режиму химиотерапии с использованием комбинированного ПТП в лечебном учреждении ФСИН.

При использовании программы анализа данных AtteStat 12.5 вычислялись медиана с 95\%-ным доверительным интервалом, верхний и нижний квартили.

\section{Материалы и методы}

Исследование проведено среди больных $(n=34)$ с впервые выявленным деструктивным инфильтративным туберкулезом легких, наблюдаемых с момента 
поступления в лечебное исправительное учреждение ФСИН в 2007-2012 гг. У ВИЧ-отрицательных пациентов в возрасте 18-52 лет методом посева мокроты на питательные среды обнаружены МБТ. Индекс массы тела составлял 18,11-24,61. В исследование были включены пациенты, лечившиеся до получения результатов анализа мокроты на чувствительность МБТ к ПТП по 2Б-режиму химиотерапии, затем проводилась коррекция лечения. Из исследования были исключены больные, получавшие нерегулярное лечение или отказавшиеся от такового. В схеме лечения присутствовал комбинированный ПТП Ломекомб (ломефлоксацин - 200 мг, изониазид - 135 мг, пиразинамид - 370 мг, этамбутол - 325 мг, пиридоксин 10 мг), ОАО "Акрихин".

Эффективность лечения оценивалась по следующим критериям: рассасывание инфильтративных изменений, закрытие полостей деструкции в легочной ткани, прекращение бактериовыделения методом посева мокроты.

У 5 (14,7 \%) больных отмечался контакт с больным туберкулезом легких, у 2 (5,9\%) - отягощенная наследственность по туберкулезу легких. У 31 (91,2 \%) пациента заболевание выявлено при плановом рентгенологическом обследовании и начало было постепенным. У 100 \% пациентов изменения в легких были впервые выявлены в местах лишения свободы: у $31(91,2 \%)$ - в медицинской части исправительного учреждения, у $3(8,8 \%)$ - в следственном изолятоpe. У 31 (91,2 \%) больного имелось полное среднее образование, у 3 - неполное среднее; 1 пациент состоял в браке, остальные не состояли.

Диагноз у 100 \% пациентов был установлен специализированной врачебной комиссией лечебного исправительного учреждения. В качестве сопутствующего заболевания у 2 (5,9\%) пациентов установлен хронический вирусный гепатит С, 33 (97,1 \%) больных были курильщиками со стажем от 4 до 36 лет. Все больные злоупотребляли крепким чаем, 4 (11,8 \%) ранее страдали алкоголизмом, 6 (17,6\%) употребляли наркотики; 1 судимость отмечена у 17 (50,0 \%), у остальных $-\geq 2$; продолжительность пребывания в местах лишения свободы варьировала от 4 мес. до 20 лет, у $32(94,1 \%)-\geq 1$ года, у $50 \%$ обследуемых $>3$ лет.

\section{Результаты}

Распространенность инфильтрации 1-2 сегментов легких определялась у 15 (44,1 \%), 1-2 долей легких у $19(55,9 \%)$; у 30 (88,2 \%) пациентов - умеренной интенсивности, у 25 (73,5\%) - односторонняя. Размер каверн в легких у $24(70,6 \%)-\leq 2$ см, у 10 $(29,4 \%)-2-4$ см, с двусторонней локализацией у 4 (11,8 \%) больных. Осложненное течение туберкулеза в виде дыхательной недостаточности и / или кровохарканья определялось у $6(17,6 \%)$ пациентов.

Методом посева мокроты обильное бактериовыделение выявлено в 14 (41,2\%), умеренное - в 13 $(38,2 \%)$, скудное - в 7 (20,6 \%) случаях. При помощи этого же метода выявлено, что в первые 3 мес. пребывания в стационаре бактериовыделение прекратилось у 25 (73,5 \%), на 4-й месяц - у 9 (26,5 \%) пациентов. Закрытие каверн на 3-й месяц лечения произошло у 11 (32,4 \%), на 4-й или 5-й - у 21 (61,8\%), на - 8-й - у 2 обследуемых.

Лекарственно-чувствительная популяция МБТ была выявлена у 21 (61,8\%), монорезистентность МБТ - у 7 (20,6\%), полирезистентность - у 5 (14,7\%), множественная лекарственная устойчивость МБТ к основным ПТП - у 1 (2,9\%) больного.

У 2 (5,9\%) пациентов за время лечения произошло усиление (индукция) начальной лекарственной устойчивости МБТ к большему числу препаратов: при лекарственно-чувствительной популяции МБТ отмечена лекарственная устойчивость к этамбутолу и полирезистентность - к основным (изониазид + стрептомицин) и резервным (изониазид + этионамид / протионамид) ПТП.

Побочные реакции на ПТП у пациентов проявлялись в виде кожных высыпаний и эозинофилии периферической крови. При изучении характера клинических проявлений и действия побочных реакций на ПТП использовалась классификация побочных реакций на аллергические, токсические и токсикоаллергические, предложенная В.Ю.Мишиным (2003).

Клинические проявления токсических реакций в значительной мере зависят от химической структуры препарата, что в большей степени обусловливает их органоспецифичность. На этом фоне чаще всего выявляются симптомы органной патологии, наиболее характерной для каждого препарата.

Токсико-аллергические реакции отличаются разнообразием и многосимптомностью аллергических проявлений, наиболее типичные из которых - гепатит, нефрит, миокардит, различные невриты, гематологические сдвиги, диспепсии, сочетающиеся с аллергическими симптомами. Токсико-аллергическое побочное действие чаще приобретает затяжное течение и труднее поддается корригирующей терапии.

Устранимые побочные реакции были выявлены у $33(97,1 \%)$ пациентов. Наиболее часто встречались токсико-аллергические реакции - у 23 (67,6\%), токсические 7 (20,6\%), аллергические отмечены у $3(8,8 \%)$ пациентов. Крапивница определялась у $6(17,6 \%)$ больных, у 5 из них - в сочетании с эозинофилией. Эозинофилия периферической крови отмечена у $25(73,5 \%)$ пациентов, причем в 1 случае она достигала $42 \%$; тошнота, рвота и боли в эпигастрии после приема ПТП - в 4 (11,8 \%) случаях. Повышение трансаминаз в крови лабораторно определялось у 28 (82,4 \%) больных: у $16(47,1 \%)$ - в 3 раза выше нормальных показателей, у $9(26,5 \%)$ - в 3-5 раз, у $3(8,8 \%)-\geq 5$ раз. Все побочные реакции устранялись при назначении симптоматической терапии без отмены стандартной схемы химиотерапии.

\section{Заключение}

В лечебных учреждениях ФСИН у больных деструктивным инфильтративным туберкулезом легких с отрицательным ВИЧ-статусом, получавших лечение 
по 2Б-режиму химиотерапии с использованием комбинированного ПТП Ломекомб, методом посева мокроты отмечено прекращение бактериовыделения и закрытие каверн в первые 3 мес. пребывания в стационаре. Среди нежелательных побочных реакций наиболее часто встречались токсико-аллергические, реже - токсические и аллергические, крапивница, эозинофилия периферической крови и повышение трансаминаз в крови.

Заявление о конфликте интересов: никаких прямых или косвенных финансовых отношений с ОАО "Акрихин" автор не имеет.

\section{Литература}

1. Приказ МЗ РФ № 109 от 21 марта 2003 года. "О совершенствовании противотуберкулезных мероприятий в Российской Федерации". М., 2003.
2. Мишин В.Ю. Туберкулез легких с лекарственной устойчивостью возбудителя. М.: ГЭОТАР-Медиа, 2009.

3. Мишин В.Ю. Медикаментозные осложнения комбинированной химиотерапии туберкулеза легких. М.: ООО "Медицинское информационное агентство", 2007.

4. Перельман М.И. (ред.). Фтизиатрия: Национальное руководство. М.: ГЭОТАР-Медиа, 2010.

Информация об авторе

Боровицкий Владислав Семенович - к. м. Н., врач-фтизиатр учреждения ФКУ ЛИУ-12 УФСИН РФ по Кировской области; тел.: (83361) 4-60-39, доп. 2-29; e-mail: qwertyuiop54@yandex.ru 